\title{
Long term survival of patients mobilised early after acute myocardial infarction
}

\author{
R R WEST, ^ A H HENDERSON† \\ From the Departments of ${ }^{\star}$ Community Medicine and + Cardiology, Welsh National School of Medicine, Cardiff
}

SUMMARY A Welsh multicentre trial of early (fifth day) compared with late (tenth day) mobilisation in 742 patients after uncomplicated myocardial infarction, reported previously, found that there were no significant differences in survival during the first year, but a partial follow up beyond the first year survival showed a significantly reduced survival during the second and third years among patients mobilised early. A full 10 year follow up of all patients admitted to the trial was therefore carried out. A small difference in survival was confirmed, which reached about $5 \%$ at four years; but the difference was not statistically significant. Further analysis suggested the possibility of real differences in survival in certain subgroups, but the present evidence was not sufficient to provide contraindication to mobilisation five days after uncomplicated myocardial infarction.

Since Levine and Lown advocated armchair treatment for patients with acute coronary thrombosis ${ }^{1}$ there has been a progressive reduction in the average duration of bed rest. There have been several randomised trials of duration of bed rest and duration of stay in hospital (cited in ${ }^{2}$ ). In the previously reported Welsh multicentre trial of early mobilisation after uncomplicated acute myocardial infarction 742 patients were randomised to five days or to 10 days of bed rest. The early and late mobilisation groups were comparable, and no significant differences in mortality or in morbidity in the first year were found. ${ }^{2}$ Similar smaller trials have shown no disadvantage of early mobilisation either in mortality or in morbidity during shorter follow up periods, usually of six weeks to six months (cited in ${ }^{2}$ ). In our Welsh trial, however, follow up information was available for some patients beyond one year, because the intended one year follow up was inadvertently delayed. An unexpected finding from that incomplete late follow up was that the survival rates of the two groups diverged during the second and third years after trial entry, with those mobilised early having significantly higher mortality. The finding has given rise to some concern about the advisability of early mobilisation. ${ }^{3}$ We report the full follow up data eight to 10 years after admission to the trial.

Requests for reprints to Dr R R West, Department of Community Medicine, Welsh National School of Medicine, Heath Park, Cardiff CF4 4XN.

Accepted for publication 10 October 1984

\section{Patients and methods}

The original trial comprised 742 patients aged $<70$ years with uncomplicated acute myocardial infarction in 1973-74 in 12 district general hospitals throughout Wales under the care of 31 consultants, mobilised on either the fifth or the tenth day after the onset of pain. Acute myocardial infarction was defined on typical clinical features, electrocardiographic evidence of probable infarction (World Health Organisation criteria ${ }^{4}$ ), and serum enzyme activities of twice the laboratory normal value. Complications that prevented inclusion were at the discretion of the consultant, although guidelines of such complications were included in the trial protocol. Information on patient identification, brief medical history, and brief clinical findings were recorded on the day of admission (generally the same as the day of onset of pain, which was defined as day 0 ) and brief clinical findings were recorded again on day 5 (the day of randomisation and admission to the trial) and again on day 10. Comparable information was collected similarly for patients with complicated acute myocardial infarction on day 5 who were excluded from the trial. Guidelines were provided for gradually increasing activity after mobilisation, necessarily allowing some variation from hospital to hospital and from patient to patient. It was recommended that patients be discharged home one week after mobilisation. Patients were reviewed at between six and 36 months after admission to the trial. The results of mortality and morbidity in the first year have been reported previously. ${ }^{2}$ 
In this further follow up study all patients admitted to the trial were traced to ascertain vital information via hospital, general practitioner, home address, the Office of Population Censuses and Surveys (OPCS), and the NHS Central Register, and then again via Family Practitioner Committee, general practitioner, and home address. Copies of death certificates of the deceased were obtained from the OPCS. The follow up was undertaken during March to September 1983, and survival up to eight to 10 years, depending on the date of admission (1973-4), was calculated by life table methods. ${ }^{5}$ Survival between patients mobilised on day 5 and those mobilised on day 10 was compared by the Mantel Haenszel (logrank) test. ${ }^{6}$ Further comparisons of survival by age, sex, hospital, previously recorded medical history, and clinical findings on admission were similarly made by the Mantel Haenszel test. The causes of death were compared by age, duration of survival, and mobilisation group.

The numbers of patients admitted to the two groups differed slightly; 348 were mobilised on day 5 and 394 on day 10 . This degree of inequality is not significant: the limits are 343 and 399 (at $2 \alpha=0.05$ ). Much of the inequality was contributed by two consultants, who admitted 8 and 23 and 14 and 23 patients on days 5 and 10 respectively. The former inequality is significant (limits 9 and 22) while the latter is not (limits 12 and 25). Since the inequality for the trial as a whole was not significant and since there were 31 consultants it is quite possible that a "significant" inequality could have occurred by chance for one. Nevertheless, in case there should have been any selection bias all survival calculations were reworked excluding $(a)$ the 31 patients admitted by the one consultant and $(b)$ the further 37 patients admitted by the other consultant.

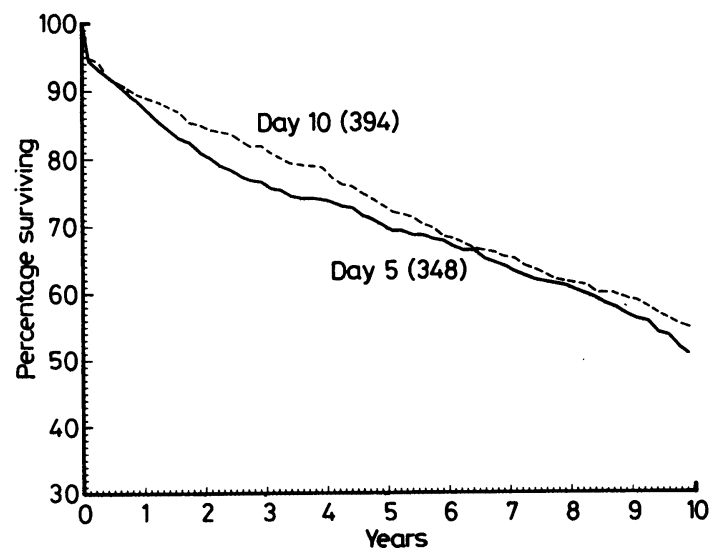

Fig. 1 Survival by day of mobilisation (day 5 or day 10). Figures in parentheses are numbers of patients.

\section{Results}

OVERALL SURVIVAL

Figure 1 shows the survival curves of patients mobilised on day 5 and those mobilised on day 10 after uncomplicated acute myocardial infarction. One year after admission to the Welsh multicentre trial $88 \%$ of those mobilised early and $89 \%$ of those mobilised late survived: the first year survivals were not statistically different. ${ }^{2}$ During the second to sixth years the survival of those mobilised early appeared to be somewhat lower than for those mobilised late, with a maximum apparent difference of $5 \%$ at four years. The difference was not, however, statistically significant (Mantel Haenszel logrank $0-4$ y $\chi^{2}=2 \cdot 3$ and $p \approx 0 \cdot 13$ ). The survival rates were more similar over the seventh to ninth years but separated again in the final year. Ten years after admission to the trial $51 \%$ of those mobilised early and $55 \%$ of those mobilised late survived: the overall $0-10$ years difference was not statistically significant. Of all 742 patients, 16 were lost to follow up before eight years and 38 and 172 were "right censored" during the ninth and tenth years respectively. The overall survival rate after 10 years was $53 \%$. The mortality rate in the first year was $11 \%$ and the annual mortality rate after the first year $4 \%$.

\section{SURVIVAL IN SUBGROUPS}

The survivals of patients mobilised on day 5 and on day 10 were compared in various subgroups (by age, sex, hospital, previous medical history, and clinical findings on admission) to look for an explanation for the apparent separation of the curves, particularly in the second to sixth years. The Table summarises the results at four years, the centre of the separation, and at 10 years. Several subgroups showed a higher mortality from about one year after infarction in the early mobilisation group: (a) patients admitted to hospital $\mathrm{F},(\mathrm{n}=110$, Mantel Haenszel $0-4 \mathrm{yr}, \mathrm{p}<0.05)$, (b) patients with previous history of hypertension $(n=83$, Fig. 2a, p<0.05), (c) patients with arrhythmia on admission $(n=137$, Fig. $2 b, p<0.01)$, and $(d)$ patients with bradycardia on admission (heart rate $<60$ beats/min, $n=58$, Fig. $2 c, p<0.02$ ). Most of these differences were at their greatest about four years after trial entry. For patients with a previous history of angina and for those with hypotension on admission the apparent differences were not significant. The differences in the opposite sense at four years (apparently lower mortality among those mobilised early) among patients admitted to hospital $\mathrm{C}$ and among the relatively few patients who had histories of previous myocardial infarction or who had tachycardia on admission were all not significant. All long term survival calculations were repeated excluding the contributions of the two consultants who entered excess patients into the late mobilisation 
Table Analysis of survival by subgroup

\begin{tabular}{|c|c|c|c|c|c|c|}
\hline & \multicolumn{2}{|c|}{ No of patients } & \multicolumn{2}{|c|}{ Survival at four years } & \multicolumn{2}{|c|}{ Survival at 10 years } \\
\hline & Day 5 & Day 10 & Day 5 & Day 10 & Day 5 & Day 10 \\
\hline $\begin{array}{c}\text { Age (yr): } \\
\quad \leqslant 44 \\
45-54 \\
55-64 \\
\geqslant 65 \\
\text { Sex: }\end{array}$ & $\begin{array}{r}44 \\
116 \\
144 \\
44\end{array}$ & $\begin{array}{r}44 \\
124 \\
160 \\
66\end{array}$ & $\begin{array}{l}0.81 \\
0.78 \\
0.74 \\
0.57\end{array}$ & $\begin{array}{l}0.86 \\
0.81 \\
0.80 \\
0.67\end{array}$ & $\begin{array}{l}0.69 \\
0.58 \\
0.43 \\
0.38\end{array}$ & $\begin{array}{l}0.71 \\
0.62 \\
0.52 \\
0.38\end{array}$ \\
\hline $\begin{array}{l}\text { Male } \\
\text { Female } \\
\text { Hospital: }\end{array}$ & $\begin{array}{r}301 \\
47\end{array}$ & $\begin{array}{r}330 \\
64\end{array}$ & $\begin{array}{l}0.73 \\
0.83\end{array}$ & $\begin{array}{l}0.78 \\
0.84\end{array}$ & $\begin{array}{l}0.48 \\
0.65\end{array}$ & $\begin{array}{l}0.54 \\
0.54\end{array}$ \\
\hline $\begin{array}{l}\text { Hospital: } \\
\text { A } \\
\text { B } \\
\text { C } \\
\text { D } \\
\text { E } \\
\text { F } \\
\text { Six others }\end{array}$ & $\begin{array}{l}59 \\
49 \\
49 \\
39 \\
32 \\
54 \\
66\end{array}$ & $\begin{array}{l}63 \\
54 \\
52 \\
45 \\
54 \\
56 \\
70\end{array}$ & $\begin{array}{l}0.68 \\
0.75 \\
0.82 \\
0.87 \\
0.75 \\
0.69 \\
0.68\end{array}$ & $\begin{array}{l}0.79 \\
0.78 \\
0.67 \\
0.77 \\
0.81 \\
0.88 \\
0.80\end{array}$ & $\begin{array}{l}0.36 \\
0.43 \\
0.68 \\
0.49 \\
0.52 \\
0.59 \\
0.45\end{array}$ & $\begin{array}{l}0.54 \\
0.58 \\
0.47 \\
0.51 \\
0.60 \\
0.62 \\
0.52\end{array}$ \\
\hline $\begin{array}{l}\text { History of: } \\
\text { Acute myocardial infarction } \\
\text { Angina } \\
\text { Hypertension }\end{array}$ & $\begin{array}{l}10 \\
90 \\
29\end{array}$ & $\begin{array}{r}8 \\
126 \\
54\end{array}$ & $\begin{array}{l}0.70 \\
0.60 \\
0.48\end{array}$ & $\begin{array}{l}0.50 \\
0.68 \\
0.72\end{array}$ & $\begin{array}{l}0.40 \\
0.32 \\
0.34\end{array}$ & $\begin{array}{l}0.38 \\
0.48 \\
0.44\end{array}$ \\
\hline $\begin{array}{l}\text { Risk features: } \\
\mathrm{BP} \geqslant 180 \mathrm{~mm} \mathrm{Hg} \\
\mathrm{BP}<120 \mathrm{~mm} \mathrm{Hg} \\
\mathrm{HR} \geqslant 120 \mathrm{beats} / \mathrm{min} \\
\text { HR }<60 \text { beats } / \mathrm{min} \\
\text { Arrhythmia: } \\
\text { Severe cardiac pain } \\
\text { Severe dyspnoea } \\
\text { All patients }\end{array}$ & $\begin{array}{r}51 \\
47 \\
24 \\
18 \\
55 \\
47 \\
15 \\
348\end{array}$ & $\begin{array}{r}59 \\
64 \\
14 \\
40 \\
82 \\
70 \\
13 \\
394\end{array}$ & $\begin{array}{l}0.76 \\
0.70 \\
0.63 \\
0.72 \\
0.67 \\
0.74 \\
0.47 \\
0.74\end{array}$ & $\begin{array}{l}0.71 \\
0.82 \\
0.43 \\
0.95 \\
0.87 \\
0.75 \\
0.46 \\
0.79\end{array}$ & $\begin{array}{l}0.43 \\
0.53 \\
0.21 \\
0.65 \\
0.45 \\
0.58 \\
0.20 \\
0.51\end{array}$ & $\begin{array}{l}0.44 \\
0.65 \\
0.21 \\
0.68 \\
0.57 \\
0.47 \\
0.21 \\
0.55\end{array}$ \\
\hline
\end{tabular}

BP, blood pressure; HR, heart rate.

group. For both of them the survival rates of the relatively few patients entered into the early mobilisation group were unusually favourable, which suggests possible bias. Exclusion of these data accordingly resulted in a widening of the difference in survival in the trial but not to the point of significance (Mantel Haenszel $0-4 y, p \approx 0.08$ ). Survivals were compared also in the subgroups after exclusion of the data from these two consultants, and these exclusions also resulted in widening of the differences but not enough to change the levels of significance.

\section{LONG TERM SURVIVAL}

The long term survivals by age of patients admitted to hospital for acute myocardial infarction, who were alive and uncomplicated on the fifth day after the onset of cardiac pain, are summarised by pooling the results of early and late mobilisation groups (Fig. 3). After 10 years $70 \%$ of patients age $\leqslant 44,60 \%$ of those aged $45-54,48 \%$ of those aged $55-64$, and $38 \%$ of those aged 65-69 were still living. Only 18 patients admitted to the trial had experienced previous acute myocardial infarction, and their 10 year survival was $39 \%$ (not significantly lower than the $53 \%$ for the trial as a whole owing to the small numbers). Two hundred and sixteen patients had previous angina with a 10 year survival of $41 \%(p<0.0001)$, and 83 had histories of hypertension with a 10 year survival of $41 \%$ $(p<0.01)$. Of the potential "risk features" on admission to hospital, tachycardia (heart ràte $\geqslant 120$ beats/ $\min$ ) conferred a lower than average survival (21\% survival at 10 years, $p<0.001$ ) and so did severe dyspnoea $(24 \%$ survival at 10 years, $p<0.01)$.

\section{CAUSES OF DEATH}

The causes of death (Ic, Ib, or Ia on the death certificate) were described as $(a)$ heart disease (ICD $410-414) 71 \%$, (b) other circulatory diseases (ICD 390-405 and 415-459) 18\% (mostly hypertension, cerebrovascular disease, and arteriosclerosis), and (c) other causes $11 \%$ (mostly cancer). There were slightly more deaths from heart disease and fewer from other circulatory diseases among patients mobilised early: $74 \%$ and $16 \%$ respectively for day 5 compared with $68 \%$ and $19 \%$ for day 10 , but these differences were not statistically significant. There were fewer deaths from heart disease and more from other causes (group c) in old patients; $59 \%$ and $20 \%$ respectively of those aged over $65(p<0.05)$. There were more deaths due to heart disease during the first year $(84 \%)$ and more deaths from other circulatory disease $(22 \%)$ and other causes (14\%) during the second to sixth years $(\mathrm{p}<0.02)$. 


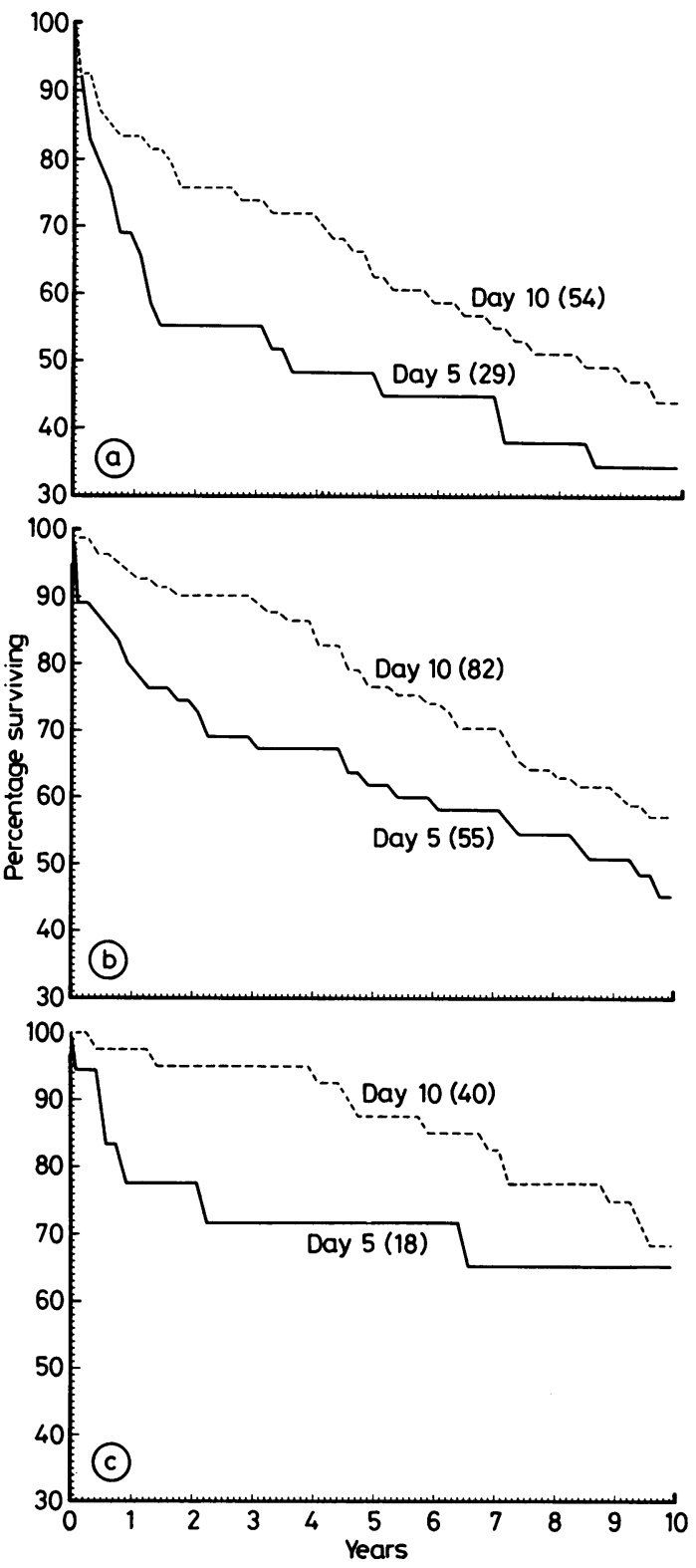

Fig. 2 Survival of patients (a) previously treated for hypertension, (b) with arrhythmias on admission, and (c) with bradycardia on admission according to day of mobilisation. Figures in parentheses are numbers of patients.

\section{Discussion}

This 10 year follow up of the Welsh multicentre trial of early mobilisation after uncomplicated myocardial

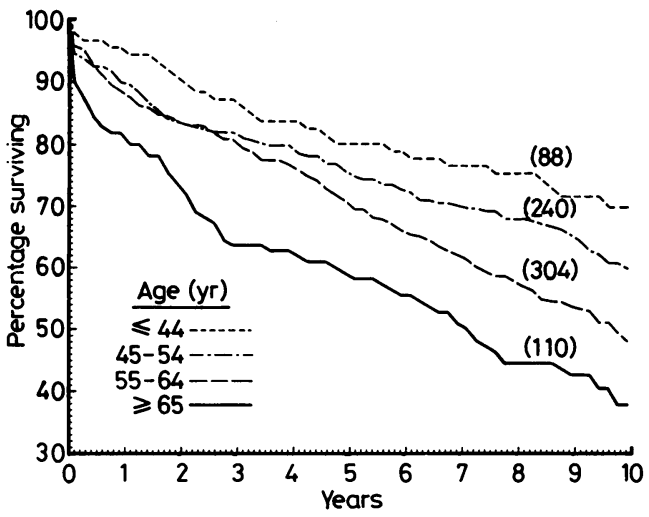

Fig. 3 Survival by age group. Figures in parentheses are numbers of patients.

infarction has shown that the lower survival after early mobilisation on the fifth day compared with late mobilisation on the tenth day that appeared during the partial 2-3 year follow up was not significant in the trial as a whole. A small non-significant difference in survival between the early and late mobilisation groups was confirmed, reaching a maximum of about $5 \%$ at four years. Subgroups of patients were identified with significantly lower survival after early mobilisation: patients admitted to hospital $F$, patients with a history of hypertension, and patients with bradycardia or arrhythmia on admission to hospital. Only the last two of these groups overlapped significantly; 28/137 with arrhythmia also had bradycardia.

Overall mortality after the fifth day for patients with uncomplicated myocardial infarction was $11 \%$ in the first year and approximately $4 \%$ a year thereafter. This is marginally less than previously reported mortality rates after acute myocardial infarction, although close comparisons are not possible because of differences between series. ${ }^{7-12}$ It also compares quite favourably with the expected mortality of about $2 \%$ in the normal population of the same sex and age distribution. ${ }^{13}$

The early and late mobilisation groups were generally comparable. During the trial all participating centres were visited periodically (by RRW), and the trial protocol was described to new house officers when appointed. Patient admissions were monitored centrally: deviations from the prenumbered sequence of randomisation cards were noted and the numbers of trial inclusions were compared with Hospital Activities Analysis (HAA) records of admissions for each consultant. Participating centres were sent progress reports and were questioned regarding any deviations from the prenumbered sequence, incomplete forms, or unusually low proportions of admis- 
sions to the trial. The non-significant excess of patients mobilised late has been shown to be attributable to entries on behalf of two of the 31 participating consultants. Exclusion of data from these sources resulted in a slight widening of the differences in survival but not to the point of significance.

The significantly lower survival after early mobilisation in four of the 23 subgroups compared in the Table, the levels of significance of the survival differences, and the heightening of the differences after exclusion of data from the two consultants whose distribution of admitted patients showed possible bias taken together suggest that the differences may be more than a random consequence of multiple comparisons. It is possible that there is a small but "real" disadvantage of early mobilisation in terms of late survival, which could achieve statistical significance only in future larger trials. The overall difference, however, was maximal at four years, whereas a "real" difference might have been expected to be maximal during the first year when mortality is highest. Furthermore, the features distinguishing three of those subgroups apparently disadvantaged by early mobilisation do not obviously identify any clinical characteristics that might reasonably be considered as potential hazards: of the four subgroups, only hypertension was associated with reduced survival in the trial as a whole. The overall difference was at no time large. We believe that the evidence is not sufficient to contraindicate mobilisation as early as the fifth day after uncomplicated myocardial infarction.

The late follow up study was supported by a grant from the Welsh scheme for the development of health and social research. We thank Mrs D A Evans for painstakingly following up each trial entrant.

\section{References}

1 Levine SA, Lown B. "Armchair" treatment of acute coronary thrombosis. FAMA 1952; 148: 1365-9.

2 West RR, Henderson AH. Randomised multicentre trial of early mobilisation after uncomplicated myocardial infarction. Br Heart F 1979; 42: 381-5.

3 Evans DW. Early ambulation after myocardial infarction. $\mathcal{F} R$ Coll Physicians (Lond) 1983; 17: 217-9.

4 World Health Organization. Hypertension and coronary heart disease: classification and criteria for epidemiological studies. WHO Tech Rep Ser 1959; No. 168.

5 Armitage P. Statistical methods in medical research. Oxford: Blackwell, 1971.

6 Peto R, Pike MC, Armitage P, et al. Design and analysis of randomized clinical trials requiring observation of each patient. II. Analysis and examples. $\mathrm{Br} \mathcal{F}$ Cancer 1977; 35: 1-39.

7 Geismar P, Iversen E, Mosbech J, Deyer K. Long-term survival after myocardial infarction: a national follow-up study on 642 patients in Denmark. Int $\mathcal{F}$ Epidemiol 1973; 2: 257-63.

8 Norris RM, Caughey DE, Mercer CJ, Scott PJ. Prognosis after myocardial infarction: six-year follow up. $\mathrm{Br}$ Heart f 1974; 36: 786-90.

9 Helmers C, Lundman T, Measing R, Wester PO. Mortality pattern among initial survivors of acute myocardial infarction using life-table technique. Acta Med Scand 1976; 200: 469-73.

10 Pohjola S, Siltanen P, Romo M. Five year survival of 728 patients after myocardial infarction. Br Heart f 1980; 43: 176-83.

11 Graham I, Mulcahy R, Hickey N, O'Neill W, Daly L. Natural history of coronary heart disease: a study of 586 men surviving an initial acute attack. Am Heart f 1983; 105: 249-57.

12 Merrilees MA, Scott PJ, Norris RM. Progress after myocardial infarction: results of 15 year follow-up. $\mathrm{Br}$ Med F 1984; 288: 356-9.

13 Office of Population Censuses and Surveys. Mortality tables 1974-80 London: HMSO, 1976-1982. 